OPEN ACCESS

Edited by:

Bahar S. Razavi,

University of Kiel, Germany

Reviewed by:

Mika Tapio Tarkka,

Helmholtz Center for Environmental

Research (UFZ), Germany

Vinay Kumar,

Central University of Punjab, India

${ }^{*}$ Correspondence:

Jose Palacios

jose.palacios@upm.es

†These authors have contributed equally to this work

${ }^{\ddagger}$ Present address:

Ana Claudia Ureta,

División de Inocuidad y Calidad de Alimentos, Dirección General de

Servicios Agrícolas, Ministerio de Ganadería, Agricultura y Pesca, Montevideo, Uruguay

Specialty section:

This article was submitted to

Plant-Soil Interactions,

a section of the journal

Frontiers in Agronomy

Received: 30 January 2021 Accepted: 01 June 2021

Published: 29 June 2021

Citation:

Sotelo M, Ureta AC, Muñoz S, Sanjuán J, Monza J and Palacios J (2021) Introduction of $\mathrm{H}_{2}$-Uptake Hydrogenase Genes Into Rhizobial Strains Improves Symbiotic Nitrogen

Fixation in Vicia sativa and Lotus corniculatus Forage Legumes.

Front. Agron. 3:661534.

doi: 10.3389/fagro.2021.661534

\section{Introduction of $\mathrm{H}_{2}$-Uptake} Hydrogenase Genes Into Rhizobial Strains Improves Symbiotic Nitrogen Fixation in Vicia sativa and Lotus corniculatus Forage Legumes

\author{
Mariana Sotelo ${ }^{1 \dagger}$, Ana Claudia Ureta ${ }^{2 \neq}$, Socorro Muñoz ${ }^{3 \dagger}$, Juan Sanjuán ${ }^{3}$, Jorge Monza ${ }^{1}$ \\ and Jose Palacios ${ }^{2 *}$ \\ 1 Departamento de Biología Vegetal, Laboratorio de Bioquímica, Facultad de Agronomía, Universidad de la República, \\ Montevideo, Uruguay, ${ }^{2}$ Centro de Biotecnología y Genómica de Plantas UPM-INIA, Campus de Montegancedo, and \\ Departamento de Biotecnología-Biología vegetal, ETSIAAB, Universidad Politécnica de Madrid, Madrid, Spain, \\ ${ }^{3}$ Departamento de Microbiología del Suelo y Sistemas Simbióticos, Estación Experimental del Zaidín, CSIC, Granada, Spain
}

Biological nitrogen fixation by the Rhizobium-legume symbiosis allows the conversion of atmospheric nitrogen into ammonia within root nodules mediated by the nitrogenase enzyme. Nitrogenase activity results in the evolution of hydrogen as a result of a side reaction intrinsic to the activity of this enzyme. Some rhizobia, and also other nitrogen fixers, induce a NiFe uptake hydrogenase (Hup) to recycle hydrogen produced by nitrogenase, thus improving the efficiency of the nitrogen fixation process. In this work we report the generation and symbiotic behavior of hydrogenase-positive Rhizobium leguminosarum and Mesorhizobium loti strains effective in vetch (Vicia sativa) and birsfoot trefoil (Lotus corniculatus) forage crops, respectively. The ability of hydrogen recycling was transferred to these strains through the incorporation of hup minitransposon TnHB100, thus leading to full recycling of hydrogen in nodules. Inoculation of Vicia and Lotus plants with these engineered strains led to significant increases in the levels of nitrogen incorporated into the host legumes. The level of improvement of symbiotic performance was dependent on the recipient strain and also on the legume host. These results indicate that hydrogen recycling has the potential to improve symbiotic nitrogen fixation in forage plants.

Keywords: hup genes, Rhizobium leguminosarum, Mesorhizobium loti, legume, inoculant

\section{INTRODUCTION}

Symbiotic nitrogen fixation, carried out by rhizobia expressing nitrogenase in association with legume plants, allows reducing the use of $\mathrm{N}$ fertilizers, thus positioning legume crops as key players in sustainable agriculture (Laranjo et al., 2014). Nitrogen fertilizers used in agriculture are incorporated into plants with low efficiency (40-50\%) resulting in the release of an enormous amount of reactive nitrogen into the biosphere (Zhang et al., 2020). Forage legumes (alfalfa, clover, vetch, trefoil, etc.) can be used as cut fodder (either directly or after fermentation) or as grazed pasture, and are also relevant at a global scale for ruminant's feeding. 
Common vetch (Vicia sativa) is a multi-purpose, cool season annual legume widely used in low- to medium rainfall areas as source of both forage and grain for animal feeding, due to its high protein content (Huang et al., 2017). V. sativa has a high potential of nitrogen fixation through its association with endosymbiotic bacteria. V. rhizobia were traditionally placed within Rhizobium leguminosarum species, but systematic analysis of isolates from different regions has revealed that other rhizobial species such as $R$. sophorae and $R$. laguerreae, are also endosymbionts of this legume (Zhang et al., 2019).

Lotus is a widely spread legume genus comprising 100130 species originally native from Europe, Asia, Africa and Australia. Its current worldwide distribution is a consequence of human-driven introduction into non-native areas due to its interest as forage legume and its adaptability to different environmental stresses, which make it a relevant alternative in ecological restoration programs (Escaray et al., 2012). Just a few species, including Lotus corniculatus, L. subbiflorus, and $L$. tenuis, have been domesticated and subject to plant breeding programs for its use as forage for livestock. Among them, $L$. corniculatus is a major component of pastures in South America (Díaz et al., 2005). Lotus rhizobia are widely diverse, with over 20 species dispersed amongst several genera (Mesorhizobium, Bradyrhizobium Rhizobium, Ensifer and Aminobacter; Lorite et al., 2018). The study of the Lotus symbiosis has been greatly advanced by the establishment of $L$. japonicus as a model system for genetic and molecular studies (Tabata and Stougaard, 2014).

Growth of pastures based in forage legumes is closely associated with the rate of biological $\mathrm{N}$ fixation, since nitrogen is often the main limiting nutrient for herbage production (Phelan et al., 2015). Nitrogenase activity results in the evolution of hydrogen as a result of a side reaction of the enzyme, thus accounting for at least $25 \%$ of electrons channeled into the enzyme. As a consequence, nodules in root legumes evolve large amounts of hydrogen, which diffuses into the soil, constituting a source of inefficiency of the system; some rhizobial strains induce a hydrogenase system able to recycle the hydrogen produced by nitrogenase, thus improving the efficiency of the nitrogen fixation process (Ruiz-Argüeso et al., 2000; Palacios et al., 2005). This hydrogenase is a metalloenzyme with a complex $\mathrm{NiFe}$ heterobimetallic cofactor. As with other metalloenzymes such as nitrogenase, the synthesis of the NiFe hydrogenase is a complex process that, in the case of $R$. leguminosarum bv. viciae, requires 18 proteins whose genetic determinants ( hupSLCDEFGHIJKhypABFCDEX) are clustered in the symbiotic plasmid of this bacterium (Palacios et al., 2005). Synthesis of hydrogenase is co-regulated with nitrogenase though the action of NifA, the master regulator of nitrogen fixation genes (Brito et al., 1997).

The cloning of the whole cluster of hydrogenase genes a cosmid (Leyva et al., 1987) allowed the introduction of hydrogenuptake (Hup) activity into hydrogenase-deficient strains of different rhizobial species, including $R$. leguminosarum, $R$. etli, and Mesorhizobium loti (Brito et al., 2000). In order to avoid unstability of the introduced genes derived from its presence as an extrachromosomal entity, a mini-transposon (TnHB100) including the whole set of hup/hyp genes along with a spectinomycin resistance marker gene was generated (Bascones et al., 2000). The use of this transposon allowed the generation of transposants inducing high levels of symbiotic hydrogenase in $\mathrm{Hup}^{-}$recipient strains from B. japonicum, $R$. etli, and $R$. leguminosarum bv viciae, leading to nodules that evolved little or no hydrogen at all. In contrast, transposants obtained from Sinorhizobium meliloti and $M$. cicer carrying the same transposon expressed very low levels of hydrogenase activity, resulting in nodules evolving high levels of hydrogen (Bascones et al., 2000).

The evaluation of the effect of hydrogen recycling has been carried out in several systems, and positive effects on the level of nitrogen fixation had been shown in different legumes such as cowpea, and common beans (Baginski et al., 2005; Torres et al., 2020). These experiments had been carried out with grain legumes, and there are scarce data available on the effect of hydrogen recycling on forage legumes. Rhizobial strains effective in alfalfa and in clover lack hydrogenase activity. Strategies for heterologous expression of hup genes, either through plasmid transfer or TnHB100 transposon insertion, have been attempted without much success. The model S. meliloti / alfalfa system does not express hydrogenase under symbiotic conditions, even though vegetative cells of the same Sinorhizobium strain can express high levels of hydrogenase activity (Brito et al., 2002), so it was important to elucidate whether the same system can also improve the growth of forage legumes in which hydrogenase is expressed. In this work we have incorporated the $R$. leguminosarum hydrogenase genes into rhizobial strains effective on two forage legumes permissive for hydrogenase expression (Lotus and Vicia), and the effect of hydrogenase activity on symbiotic performance of the new strains has been determined.

\section{MATERIALS AND METHODS}

\section{Bacterial Strains, Plasmids, and Growth Conditions}

R. leguminosarum Rlv13 and Rlv21 were isolated from $V$. sativa root nodules at Zaidín Estacion Experimental (Granada, Spain). M. loti U261 (=NZP2037, Irisarri et al., 1996) was obtained from the Department of Scientific and Industrial Research, Palmerston South, New Zealand. Rhizobium and Mesorhizobium strains were grown at $28^{\circ} \mathrm{C}$ in tryptone-yeast extract (TY), yeastmanitol broth (YMB), or Rhizobium minimal media (Rmin) (Bascones et al., 2000). Escherichia coli strains were grown at $37^{\circ} \mathrm{C}$ in Luria-Bertani medium supplemented with the corresponding antibiotics. Minitransposon TnHB100, carrying the entire $R$. leguminosarum hup cluster was transferred into (Meso)Rhizobium strains by conjugation as previously described (Bascones et al., 2000). For bacterial conjugations, fresh cell cultures of E. coli S17.1 $\lambda \operatorname{pir}(\mathrm{pTnHB100)}$ donor (Simon et al., 1983 ) and rhizobial recipient strains were mixed on TY plates and incubated overnight at $28^{\circ} \mathrm{C}$. Transconjugants were selected on Rmin plates supplemented with $200 \mu \mathrm{g} / \mathrm{ml}$ of spectinomycin.

\section{Plant Material and Growth Conditions}

Seeds of $L$. corniculatus $c v$. La Estanzuela, L. tenuis, $L$. subbiflorus, and L. uliginosus were surface sterilized with $10 \%$ 
sodium hypochlorite and pregerminated at $28^{\circ} \mathrm{C}$ for 2 days in the dark. $V$. sativa cv. Filón seeds were sterilized with ethanol/sodium hypochlorite treatment and pregerminated as previously described (Brito et al., 2000). Three-day old seedlings were sown in pots containing vermiculite supplied with a nitrogen-free nutrient solution (Handberg and Stougaard, 1992; Brito et al., 1994) and inoculated with liquid cultures of rhizobial strains. Plants were maintained in a growth chamber under controlled conditions (16/8 h light/dark; Monza et al., 1992; Brito et al., 2000). Bacteroid supensions were prepared from freshly detached nodules as previously described (Brito et al., 2008).

\section{Recombinant DNA Techniques}

Plasmid DNA preparations, restriction enzyme digestions, DNA cloning, transformation of DNA into E. coli, agarose gel electrophoresis, Southern hybridizations, and PCR amplifications were performed by standard methods (Sambrook and Russell, 2002). Total DNA from rhizobial strains was isolated as described (Bascones et al., 2000). For the determination of nucleotide sequence flanking the TnHB100 insertions, the region was first cloned as a PstI restriction fragment in a pBluescript vector plasmid (Agilent Technologies, La Jolla, CA), and the DNA sequence was determined using a primer complementary to the $3^{\prime}$ end of the spectinomycin resistance cassette $\left(5^{\prime}\right.$ GCTGGCTTTTTCTTGTTATCG-3'). Transposon insertions in $\mathrm{Rlv} 13 \mathrm{H} 9$ and Rlv21H19 were located in genes encoding potential galactonate dehydratase/epimerases highly similar to protein RLV_6446 from R. leguminosarum bv viciae (Sanchez-Canizares et al., 2018). These proteins are moderately expressed in pea and lentil bacteroids induced by Rlv UPM791 (Duran et al., 2021), and might function in carbon metabolism pathway, so a potential effect of the gene inactivation on bacterial performance cannot be excluded. In contrast, insertion in Rlv13H6 was located in an intergenic region, with no similarity to described genes, whereas Rlv21H10 carried TnHB100 insertion in a hypothetical protein not expressed in bacteroids as deduced from a recent proteomic analysis (Duran et al., 2021). In the case of $\mathrm{Ml} \mathrm{U} 261 \mathrm{H} 4$, the site of insertion was located in an intergenic region downstream of a potassium uptake gene ( $k u p)$ located at positions 2366770-2368683 of the genome (Kelly et al., 2014).

The removal of spectinomycin cassette from Rlv13 and Rlv21 TnHB100-containing derivatives was carried out as described (Bascones et al., 2000). Briefly, DNA regions flanking the resistance marker on each strain were obtained and fused to hupS upstream region by restriction cloning in pK18mobSac suicide vector (Schäfer et al., 1994). Then, the plasmid was conjugated into the strains carrying the TnHB100 insertion, and a double recombination event excising $\mathrm{Spc}^{\mathrm{R}}$ marker was obtained based on the selection provided by $\operatorname{sac} B$ gene.

\section{Determination of Nitrogenase and Hydrogenase Activities and Plant Tests}

Nitrogenase activity was determined by the acetylene reduction assay, and hydrogenase activity was estimated by measuring bacteroid hydrogen uptake amperometrically, or hydrogen evolution from nodules by gas chromatography (Brito et al., 2000, 2008) using detopped nodulated roots from 35 day-old plants.
Plant dry weight was measured after maintaining shoots in an oven at $80^{\circ} \mathrm{C}$ for $48 \mathrm{~h}$. Nitrogen content of Lotus plants was determined from detached leaves collected after 40, 60 and 70 days growing period and analyzed for total nitrogen with a mass spectrometer (IRMS Micromass Isochrom) at SIDI- Laboratorio de Isótopos Estables (Montevideo, Uruguay). Nitrogen content was calculated according with IAEA (IAEA, 2001). Nitrogen content of Vicia shoots was determined by a combustion method using a nitrogen analyzer (FP-528-LECO). Experiments were established in a completely random design with at least three replicates. Data were analyzed using ANOVA and means were compared using Fisher's least significant difference (LSD) test at $5 \%$ probability level.

\section{RESULTS}

\section{Generation of Hydrogen-Recycling Strains}

In order to analyze the potential effect of hydrogen recycling in symbiotic performance of forage legumes, the R. leguminosarum hydrogenase gene cluster was introduced into strains effective in Vicia sativa ( $R$. leguminosarum bv viciae Rlv13 and Rlv21) and in L. corniculatus (Mesorhizobium loti U261, a broad-range Lotus inoculant strain). Stable insertion of hup gene package into the recipient strains was carried using transposon TnHB100. Following conjugation with E. coli

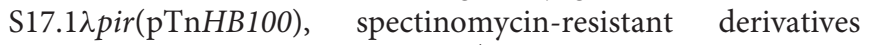
arose at frequencies of $\mathrm{ca} \cdot 10^{-4} /$ recipient (Rlv strains) or $10^{-8}$ /recipient (Ml U261). The presence of hup genes in spectinomycin-resistant transconjugants was confirmed through identification of hupS-hybridizing bands in Southern experiments (Supplementary Figure 1) or through PCR amplification of specific bands corresponding to hypB gene using adequate primers (data not shown).

The ability of transposants to effectively recycle hydrogen evolved by nitrogenase was assessed in several derivatives per each recipient strain. In the case of strains effective in $V$. sativa, four derivatives obtained from each of Rlv13 and Rlv21 strains were analyzed for hydrogenase and nitrogenase activities in vetch nodules (Table 1). With one exception, all transconjugants from $R l v$ strains showed high levels of nitrogenase activity. The exception was the Rlv13 derivative $\mathrm{Rlv} 13 \mathrm{H} 24$, which showed a poor symbiotic performance, attributed to a potential deleterious effect of the insertion. Although there were differences in the levels of hydrogenase activity induced in each case, in both sets of strains we found derivatives with levels of hydrogenase activity high enough as to fully recycle the hydrogen evolved by nitrogenase, thus resulting in nodules with no detectable hydrogen evolution: Rlv13H6 and H9, and Rlv21H10 and H19 (Table 1). Insertion sites were determined for these four derivatives (see Materials and Methods), and derivatives Rlv 13H6 and Rlv21H10, bearing insertions with no predicted effect on bacteroid physiology were selected for the analysis of the effect of hydrogen recycling on vetch productivity.

Transposon $\mathrm{TnHB100}$ carries a $\mathrm{Spc}^{\mathrm{R}}$ determinant whose presence in bacteria designed to be used as inoculant in the field is not desirable. In order to generate marker-free derivatives more acceptable for field release, strains Rlv13H6 and Rlv21H10 were 
TABLE 1 | Nitrogenase and hydrogenase activities of wild-type and engineered strains incorporating hydrogenase genes from R. leguminosarum UPM791.

\begin{tabular}{lccc}
\hline Strain & Nitrogenase activity & Hydrogenase activity & $\mathbf{H}_{\mathbf{2}}$ evolution $^{\mathbf{a}}$ \\
\hline R. leguminosarum/Vicia sativa & & \\
Rlv13 (WT) & $51.6 \pm 2.3$ & $<50$ & $14.1 \pm 0.7$ \\
Rlv13H6 & $45.2 \pm 5.5$ & $1,187 \pm 321$ & $<0.05$ \\
Rlv13H9 & $60.2 \pm 0.2$ & $1,272 \pm 90$ & $<0.05$ \\
Rlv13H21 & $30.5 \pm 1.3$ & $609 \pm 198$ & $1.2 \pm 0.1$ \\
Rlv13H24 & $<10$ & $<50$ & $<0.05$ \\
Rlv21 (WT) & $37.9 \pm 2.3$ & $<50$ & $8.7 \pm 0.2$ \\
Rlv21H10 & $26.8 \pm 0.5$ & $1,117 \pm 546$ & $<0.05$ \\
Rlv21H16 & $44.1 \pm 0.2$ & $1,044 \pm 506$ & $2.5 \pm 0.7$ \\
Rlv21H19 & $41.4 \pm 1.1$ & $1,043 \pm 473$ & $<0.05$ \\
Rlv21H22 & $35.4 \pm 0.3$ & $198 \pm 18$ & $8.1 \pm 0.8$ \\
Mesorhizobium loti/Lotus corniculatus & & \\
MI U261 (WT) & $2.4 \pm 0.8$ & n.d. & $1.07 \pm 0.4$ \\
MI U261H4 & $0.6 \pm 0.2$ & n.d. & $<0.05$ \\
MI U261H6 & $1.4 \pm 0.3$ & n.d. & $0.6 \pm 0.1$ \\
MI U261H15 & $1.5 \pm 0.1$ & n.d. & $0.5 \pm 0.3$ \\
MI U261H16 & $1.2 \pm 0.1$ & n.d. & $0.8 \pm 0.1$ \\
MI U261H23 & $1.0 \pm 0.1$ & n.d. & $0.6 \pm 0.3$ \\
MI U261H 25 & $2.1 \pm 0.7$ & n.d. & $0.3 \pm 0.1$ \\
\hline & & &
\end{tabular}

a Values are expressed in $\mu$ moles. $h^{-1}$. (g nodule fresh weight $)^{-1}$, and represent the mean of at least three determinations \pm S.D.

${ }^{b}$ Values are expressed in nmoles of $\mathrm{H}_{2} \cdot h^{-1}$. (mg protein $)^{-1}$.

n.d., not determined.

further engineered for the removal of $\mathrm{Spc}^{\mathrm{R}}$ determinant by a double recombination event carried out as described in Materials and Methods. The absence of the spectinomycin resistance cassette in the resulting strains was confirmed by Southern hybridization of genomic DNA using a probe internal to the $\mathrm{Spc}^{\mathrm{R}}$ gene (Supplementary Figure 1). Both strains, designated as Rlv13H6DS and Rlv21H10DS, induced nodules with levels of nitrogenase activity similar to those in the strains bearing the $\mathrm{Spc}^{\mathrm{R}}$ determinant. Bacteroids from these strains showed high levels of hydrogenase activity that fully recycled the nitrogenasederived hydrogen (data not shown).

In the case of $M$. lot $i$ U261 derivatives, 6 transconjugants were selected to assess the expression of the introduced hup genes in symbiosis with L. corniculatus as the legume host. Each of the transconjugants was used as inocula for L. corniculatus plants, and the levels of nitrogenase activity and hydrogen evolution from nodules were determined (Table 1). Levels of nitrogenase activity in the transconjugant strains did not show significant differences with that from the wild type. Nodules induced by the hup-containing derivatives showed significant reductions of the level of hydrogen evolution as compared to nodules induced by the wild-type strain (Table 1). The complete suppression of hydrogen evolution, indicating full recycling of nitrogenaseproduced hydrogen, was detected in one of the transconjugants ( $\mathrm{Ml} \mathrm{U} 261 \mathrm{H} 4)$. Inspection of the corresponding genomic region (see Materials and Methods section) revealed that this insertion is likely in an intergenic region not affecting the expression of any other gene.
TABLE 2 | Effect of the introduction of hup genes on symbiotic performance of $R / v$ strains in association with $V$. sativa plants.

\begin{tabular}{lccc}
\hline Strain $^{\mathbf{a}}$ & N content (mg/plant) & \% increase & SDW (mg/plant) \\
\hline Rlv13 & $15.6 \pm 0.8 \mathrm{a}$ & & $338 \pm 71 \mathrm{a}$ \\
Rlv13H6 & $18.6 \pm 1.0 \mathrm{~b}$ & 19 & $420 \pm 44 \mathrm{a}$ \\
Rlv13H6DS & $17.8 \pm 1.0 \mathrm{~b}$ & 14 & $411 \pm 51 \mathrm{a}$ \\
Rlv21 & $16.1 \pm 1.2 \mathrm{a}$ & & $348 \pm 40 \mathrm{a}$ \\
Rlv21H10 & $16.0 \pm 0.7 \mathrm{a}$ & $343 \pm 30 \mathrm{a}$ \\
Rlv21H10DS & $16.9 \pm 1.1 \mathrm{a}$ & $360 \pm 50 \mathrm{a}$ \\
\hline
\end{tabular}

Values are the mean of 4 replicates \pm S.E. Values followed by a different letter indicate significant differences with the corresponding wild-type strain according to Fisher's L.S.D test.

\section{Analysis of the Effect of Hydrogen Recycling on Plant Productivity}

In order to determine the effect of the hydrogen recycling on symbiotic performance of the vetch/R. leguminosarum bv viciae system, $V$. sativa plants were inoculated with the wild type strains Rlv13 and Rlv21 and with the hup-engineered derivatives obtained from them and described above. Inoculated plants were maintained in a growth chamber, and shoot dry matter and nitrogen accumulation were determined 30 days after inoculation. In this analysis, hydrogen-recycling strains derived from Rlv13 showed significant increases $(p<0.05)$ in $\mathrm{N}$ fixed per plant (Table 2). Values of shoot dry weight also showed marked increases $(24.1 \%$ and $21.7 \%$, respectively) although in this case the higher variability of the data led to a lower significance of the differences $(p<0.1)$. In the case of strain Rlv21, derivatives incorporating the ability of full hydrogen recycling did not show significant variations of any of the two productivity parameters analyzed. These data suggest that the rhizobial background is relevant for the expression of the benefits associated to hydrogen recycling.

Symbiotic performance of $M$. loti U261 and its derivative strain U261H4 were compared in L. corniculatus plants grown under controlled conditions. Plant shoot dry weight, and $\mathrm{N}$ content of the shoots were determined at 40, 60, and 70 days after inoculation. 60- and 70-day old plants inoculated with the engineered strain showed levels of nitrogen accumulation significantly higher than those inoculated with the wild-type strain. This result was consistently observed in three independent experiments carried out under controlled chamber conditions. The increase in nitrogen was accompanied with an increase in dry weight at 70 days (Table 3). At 40 days plants showed higher values of $\mathrm{N}$ accumulation, but the variability of the data made these differences not statistically significant.

Since, M. loti U261 is effective in other Lotus species of agronomical interest (Gonnet and Díaz, 2000), we also estimated the potential benefits of hydrogen recycling carried out by M. loti $\mathrm{U} 261 \mathrm{H} 4$ when in symbiosis with other 3 hosts of the same genus, namely L. tenuis, L. subbiflorus, and $L$. uliginosus. Similarly to what was observed in L. corniculatus, nodules induced by $M$. loti $\mathrm{U} 261 \mathrm{H} 4$ engineered strain showed undetectable levels of hydrogen evolution in symbiosis with 
TABLE 3 | Effect of the introduction of hup genes on symbiotic performance of M. loti U261 in association with L. corniculatus plants.

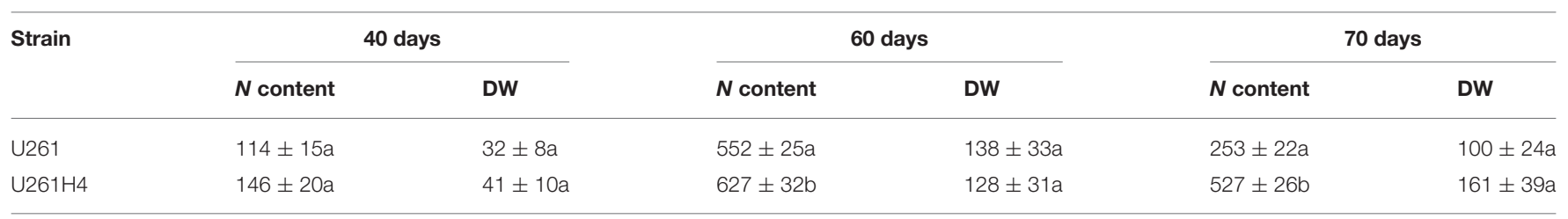

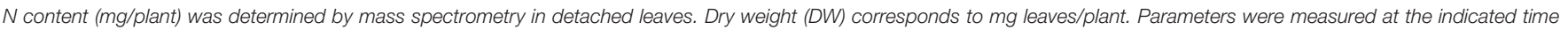
points after inoculation. Values are the mean of 3 replicates \pm S.D. Values following by different letters indicate significant differences ( $p<0.05$ ) according to a Fisher's L.S.D. test.

TABLE 4 | Effect of the introduction of hup genes on symbiotic performance of $M$. loti $\mathrm{U} 261$ strain in association with the indicated host legumes.

\begin{tabular}{|c|c|c|c|c|c|c|}
\hline Strain & \multicolumn{2}{|c|}{ Lotus tenuis } & \multicolumn{2}{|c|}{ Lotus subbiflorus } & \multicolumn{2}{|c|}{ Lotus uliginosus } \\
\hline U261H4 & $864 \pm 210 a$ & $201 \pm 56 a$ & $766 \pm 180 a$ & $187 \pm 21 a$ & $457 \pm 60 a$ & $127 \pm 19 a$ \\
\hline
\end{tabular}

N content (mg/plant) was determined by mass spectrometry in detached leaves. Dry weight (DW) corresponds to mg leaves/plant. Parameters were measured 60 days after inoculation. Values are the mean of 3 replicates \pm S.D. Values following by different letters indicate significant differences $(p<0.05)$ according to a Fisher's L.S.D. test.

these 3 hosts, whereas nodules induced by the wild type strain Ml U261 evolved large amounts of hydrogen in all cases (data not shown). These results indicate that $R$. leguminosarum hup system is expressed under symbiotic conditions in all host partners at levels high enough as to fully recycle hydrogen evolved by nitrogenase. Despite full hydrogen recycling, there were no significant differences between the wild type and U261H4 engineered strain neither in shoot dry weight nor in $\mathrm{N}$ content in symbiosis with $L$. tenuis, L. subbiflorus, $L$. uliginosus at 60 days of cultivation (Table 4), indicating a relevant role for the host on the effect of hydrogen-recycling on nitrogen fixation.

\section{DISCUSSION}

\section{Hydrogenase Activity and Forage Legume Productivity}

Forage legumes constitute a relevant input of protein for the sustainable feeding of livestock, a crucial issue in a context of increased demand of livestock products (FAO, 2011; Michalk et al., 2019). The productivity of pastures is dependent on an adequate supply of nitrogen (Phelan et al., 2015), therefore ensuring optimal functioning of symbiotic nitrogen fixation is a relevant aspect for pasture management. This optimization includes the use of highly efficient rhizobial strains. Even the most efficient rhizobial strains still dedicate a minimum of $25 \%$ of electrons going through nitrogenase to reduce protons to hydrogen. In this work we have generated rhizobial strains effective in two forage legumes (Lotus and Vicia) and able to fully recycle the hydrogen evolved from nitrogenase activity in the nodules. Engineered strains were associated to levels of nitrogen fixation higher than the respective wild-type strains under controlled conditions. It has to be noted, however, that for L. tenuis and L. subbiflorus the data showed a higher level of variability which, along with the limited number of replicates, did not allow to adscribe statistical significance to the observed variation of the mean values.

Previous evidence had shown that $R$. leguminosarum hydrogenase system is expressed in nodules when the hydrogenase gene cluster is introduced into strains effective on Vicia and Lotus (Monza et al., 1997; Brito et al., 2000). In contrast, introduction of the same system into Sinorhizobium meliloti strains resulted in only residual levels of hydrogenase activity in alfalfa nodules. It was concluded that several factors, including nickel provision and effectiveness of heterologous regulators, limit the expression in different backgrounds (Brito et al., 2000). The original transposon contains a spectinomycin resistance cassette to help on the selection of transposants (Bascones et al., 2000). We have also generated derivative strains in which such marker has been deleted, thus resulting in engineered strains in which only rhizobial DNA was present. As expected, removal of $\mathrm{Spc}^{\mathrm{R}}$ tag did not change the symbiotic performance of the strains. These strains should be more amenable to its use as inoculants.

The results presented in this work indicate that the introduced ability of hydrogen recycling has the potential to increase nitrogen fixation in forage legumes, confirming the notion of hydrogen evolution as a source of inefficiency of nitrogen fixation by the Rhizobium-legume symbiosis (Evans et al., 1988). There was scarce previous information on the effect of hydrogen recycling on forage legumes. The presence of hydrogenase genes in rhizobia is highly variable depending of the system (RuizArgüeso et al., 2000), and in fact there are no reports on the presence of functional hup gene clusters in rhizobia isolated from forage legumes such as clover or alfalfa. Even in $R$. leguminosarum bv viciae the presence of hydrogenase system is highly uncommon (Fernandez et al., 2005), and so the actual evolutionary advantage of possessing such system is a matter of controversy. Now we demonstrate for the first time that the advantages of hydrogen recycling can be exploited also in forage legumes, at least under controlled conditions. The results 
obtained also indicate that both the host species and the rhizobial strain condition the existence of significant increases of fixed nitrogen associated to hydrogenase activity. Factors proposed to account for the beneficial effect of hydrogen recycling are the protection of nitrogenase against oxygen and against the detrimental effect of hydrogen, and the availability of additional energy for nitrogen fixation (Palacios et al., 2005). Additional work is required to elucidate the reasons for the observed effect of both the rhizobial background and host legume. It has to be noted that nickel provision and effectiveness of heterologous regulators for expression of hydrogenase genes have been cited before as potential limiting factors (Brito et al., 2000).

\section{Hydrogen and Soil Fertility}

The role of hydrogen evolution and hydrogen recycling in plant productivity is not a simple question. Results presented here refer to the levels of nitrogen fixed by the inoculated legume, and have been obtained in an artificial substrate without the soil microbiome. From a more integrated point of view, the positive role of hydrogen recycling in the productivity of legumes must be considered along with the potential effect of hydrogen evolved from nodules in the fertility of surrounding soil. It has been shown that the presence of hydrogen evolving nodules in legume plants inoculated with hydrogenase-negative rhizobia results in an increase of the ratio of $\mathrm{H}_{2}$-oxidizing bacteria in soil surrounding nodules, as could be expected from the presence of an additional energy substrate in the environment. In fact, a "hydrogen fertilization effect" has been proposed as a factor contributing to the observed benefit of legumes on the following crop in rotation practices (Golding and Dong, 2010). The direct addition of hydrogen to soils resulted in increases in tiller/plant and plant dry weight in barley (Dong et al., 2003). There is also one report indicating that barley crop following soybean inoculated with $\mathrm{Hup}^{-}$, hydrogen evolving B. japonicum strain resulted in higher grain yield than in the case of isogenic, hydrogen recycling strain (Dean et al., 2006). In that work an increase of hydrogen oxidation activity in soils surrounding Hup $^{-}$nodules was also detected. Changes in soil microbiome around nodules producing hydrogen are expected, and it has been recently shown that exposure of soil to hydrogen levels similar to those on the soil-nodule interface indeed causes changes in soil microbiome structure and function, including the stimulation of carbon turnover (Khdhiri et al., 2017). All

\section{REFERENCES}

Baginski, C., Brito, B., Imperial, J., Ruiz-Argüeso, T., and Palacios, J. M. (2005). Symbiotic hydrogenase activity in Bradyrhizobium sp (Vigna) increases nitrogen content in Vigna unguiculata plants. Appl. Environ. Microb. 71, 7536-7538. doi: 10.1128/AEM.71.11.7536-7538.2005

Bascones, E., Imperial, J., Ruiz-Argueso, T., and Palacios, J. M. (2000). Generation of new hydrogen-recycling Rhizobiaceae strains by introduction of a novel hup minitransposon. Appl. Environ. Microb 66, 4292-4299. doi: 10.1128/AEM.66.10.4292-4299.2000

Brito, B., Martínez, M., Fernández, D., Rey, L., Cabrera, E., Palacios, J. M., et al. (1997). Hydrogenase genes from Rhizobium leguminosarum bv. viciae are these data indicate that the potential role of hydrogen metabolism in plant productivity should be analyzed from an integrated perspective. The hydrogen-recycling strains effective in forage legumes developed in this work can be used to further study the effect of hydrogen metabolism on mixed grass-legume pastures in which the potential role of hydrogen in stimulating other crops can be analyzed in the same season as legume symbiosis occurs, so a more integrated study of the effect of nitrogen fixation on mixed pasture production can be carried out.

\section{DATA AVAILABILITY STATEMENT}

The original contributions presented in the study are included in the article/Supplementary Material, further inquiries can be directed to the corresponding author.

\section{AUTHOR CONTRIBUTIONS}

MS, AU, and SM performed experiments and analyzed data. JM and JS designed experiments, validated data and review the manuscript. JP designed experiments, validated data, wrote draft and reviewed the manuscript. All authors contributed to the article and approved the submitted version.

\section{ACKNOWLEDGMENTS}

The authors are extremely grateful to Drs. José Olivares and Tomás Ruiz-Argüeso for providing resources and intellectual support to this work for so many years in the context of EU's IMPACT and other projects. JP is funded by grant from Spain's Ministerio de Ciencia, Innovación y Universidades (RTI2018094985-B-100). JM obtained funds from Programa de Desarrollo de Ciencias Básicas and INIA-Uruguay (Project 4-componente IV), and by Sistema Nacional de Investigadores. This paper is dedicated to the memory of Tomás Ruiz-Argüeso, who passed away in March 2020 due to Covid19.

\section{SUPPLEMENTARY MATERIAL}

The Supplementary Material for this article can be found online at: https://www.frontiersin.org/articles/10.3389/fagro. 2021.661534/full\#supplementary-material controlled by the nitrogen fixation regulatory protein NifA. Proc. Natl. Acad. Sci. U.S.A. 94, 6019-6024. doi: 10.1073/pnas.94.12.6019

Brito, B., Monza, J., Imperial, J., Ruiz-Argüeso, T., and Palacios, J. M. (2000). Nickel availability and hupSL activation by heterologous regulators limit symbiotic expression of the Rhizobium leguminosarum bv. viciae hydrogenase system in Hup- rhizobia. Appl. Environ. Microb. 66, 937-942. doi: 10.1128/AEM.66.3.937-942.2000

Brito, B., Palacios, J. M., Hidalgo, E., Imperial, J., and Ruiz-Argüeso, T. (1994). Nickel availability to pea (Pisum sativum L.) plants limits hydrogenase activity of Rhizobium leguminosarum bv. viciae bacteroids by affecting the processing of the hydrogenase structural subunits. J. Bacteriol. 176, 5297-5303. doi: $10.1128 /$ jb.176.17.5297-5303.1994 
Brito, B., Palacios, J. M., Imperial, J., and Ruiz-Argüeso, T. (2002). Engineering the Rhizobium leguminosarum bv. viciae hydrogenase system for expression in freeliving microaerobic cells and increased symbiotic hydrogenase activity. Appl. Environ. Microbiol. 68, 2461-2467. doi: 10.1128/AEM.68.5.2461-2467.2002

Brito, B., Toffanin, A., Prieto, R. I., Imperial, J., Ruiz-Argüeso, T., and Palacios, J. M. (2008). Host-dependent expression of Rhizobium leguminosarum bv. viciae hydrogenase is controlled at transcriptional and post-transcriptional levels in legume nodules. Mol. Plant Microbe Interact. 21, 597-604. doi: 10.1094/MPMI-21-5-0597

Dean, C. A., Sun, W. C., Dong, Z. M., and Caldwell, C. D. (2006). Soybean nodule hydrogen metabolism affects soil hydrogen uptake and growth of rotation crops. Can. J. Plant Sci. 86, 1355-1359. doi: 10.4141/P06-082

Díaz, P., Borsani, O., and Monza, J. (2005). Lotus-Related Species and Their Agronomic Importance. Lotus Japonicus Handbook. Dordrecht, Netherlands: Springer. 25-37. doi: 10.1007/1-4020-3735-X_2

Dong, Z., W, L., Kettlewell, B., Caldwell, C. D., and Layzell, D. B. (2003). Hydrogen fertilization of soils - is this a benefit of legumes in rotation? Plant Cell Environ. 26, 1875-1879. doi: 10.1046/j.1365-3040.2003.01103.x

Duran, D., Albareda, M., Garcia, C., Marina, A. I., Ruiz-Argüeso, T., and Palacios, J. (2021). Proteome analysis reveals a significant host-specific response in Rhizobium leguminosarum bv viciae endosymbiotic cells. Mol. Cell. Proteomics 20: 100009. doi: 10.1074/mcp.RA120.002276

Escaray, F. J., Menendez, A. B., Garriz, A., Pieckenstain, F. L., Estrella, M. J., Castagno, L. N., et al. (2012). Ecological and agronomic importance of the plant genus Lotus. Its application in grassland sustainability and the amelioration of constrained and contaminated soils. Plant Sci. 182, 121-133. doi: 10.1016/j.plantsci.2011.03.016

Evans, H. J., Russell, S. A., Hanus, F. J., and Ruiz-Argüeso, T. (1988). The Importance of Hydrogen Recycling in Nitrogen Fixation by Legumes. World crops: Cool Season Food Legumes. Boston: Kluwer Academic Publ. 777-791. doi: 10.1007/978-94-009-2764-3_62

FAO (2011). Mapping supply and demand for animal-source foods to 2030. Available at: http://www.fao.org/3/i2425e/i2425e00.htm (accessed December 2020).

Fernandez, D., Toffanin, A., Palacios, J. M., Ruiz-Argüeso, T., and Imperial, J. (2005). Hydrogenase genes are uncommon and highly conserved in Rhizobium leguminosarum bv. viciae. FEMS Microbiol. Lett. 253, 83-88. doi: 10.1016/j.femsle.2005.09.022

Golding, A. L., and Dong, Z. M. (2010). Hydrogen production by nitrogenase as a potential crop rotation benefit. Environ. Chem. Lett. 8, 101-121. doi: 10.1007/s10311-010-0278-y

Gonnet, S., and Díaz, P. (2000). Glutamine synthetase and glutamate synthase activities in relation to nitrogen fixation in Lotus spp. Braz. J. Plant Physiol. 12, 195-202. doi: 10.1590/S0103-31312000000300003

Handberg, K., and Stougaard, J. (1992). Lotus-japonicus, an autogamous, diploid legume species for classical and molecular genetics. Plant J. 2, 487-496. doi: 10.1111/j.1365-313X.1992.00487.x

Huang, Y. F., Gao, X. L., Nan, Z. B., and Zhang, Z. X. (2017). Potential value of the common vetch (Vicia sativa L.) as an animal feedstuff: a review. J. Anim. Physiol. Anim. Nutr. 101, 807-823. doi: 10.1111/jpn.12617

IAEA (2001). Use of isotope and radiation methods in soil and water managment and crop nutrition. IAEA- TCS-14, Vienna. Vienna: IAEA TCS-14.

Irisarri, P., Milnitsky, F., Monza, J., and Bedmar, E. J. (1996). Characterization of rhizobia nodulating Lotus subbiflorus from Uruguayan soils. Plant Soil 180, 39-47. doi: 10.1007/BF00015409

Kelly, S., Sullivan, J., Ronson, C., Tian, R., Brau, L., Davenport, K., et al. (2014). Genome sequence of the Lotus spp. microsymbiont Mesorhizobium loti strain NZP2037. Front Stand. Genimic Sci. 9:7. doi: 10.1186/1944-3277-9-7

Khdhiri, M., Piche-Choquette, S., Trembla, J., Tringe, S. G., and Constant, P. (2017). The Tale of a neglected energy source: elevated hydrogen exposure affects both microbial diversity and function in soil. Appl. Environ. Microb. 83,e00275-e00217. doi: 10.1128/AEM.00275-17

Laranjo, M., Alexandre, A., and Oliveira, S. (2014). Legume growth-promoting rhizobia: an overview on the Mesorhizobium genus. Microbiol. Res. 169, 2-17. doi: 10.1016/j.micres.2013.09.012

Leyva, A., Palacios, J. M., Mozo, T., and Ruiz-Argüeso, T. (1987). Cloning and characterization of hydrogen uptake genes from Rhizobium leguminosarum. J. Bacteriol. 169, 4929-4934. doi: 10.1128/JB.169.11.4929-4934.1987
Lorite, M. J., Estrella, M. J., Escaray, F. J., Sannazzaro, A., Castro, I. M. V. E., Monza, J., et al. (2018). The rhizobia-lotus symbioses: deeply specific and widely diverse. Front. Microbiol. 9:2055. doi: 10.3389/fmicb.2018.02055

Michalk, D. L., Kemp, D. R., Badgery, W. B., Wu, J. P., Zhang, Y. J., and Thomassin, P. J. (2019). Sustainability and future food security-a global perspective for livestock production. Land. Degrad. Dev. 30, 561-573. doi: 10.1002/ldr. 3217

Monza, J., Díaz, P., Borsani, O., Ruiz-Argüeso, T., and Palacios, J. M. (1997). Evaluation and improvement of the energy efficiency of nitrogen fixation in Lotus corniculatus nodules induced by Rhizobium loti strains indigenous to Uruguay. World J. Microbiol. Biotech. 13, 565-571. doi: 10.1023/A:1018573527503

Monza, J., Fabiano, E., and Arias, A. (1992). Characterization of an indigenous population of rhizobia nodulating Lotus corniculatus. Soil Biol. Biochem. 24, 241-247. doi: 10.1016/0038-0717(92)90225-M

Palacios, J. M., Manyani, H., Martinez, M., Ureta, A. C., Brito, B., Bascones, E., et al. (2005). Genetics and biotechnology of the $\mathrm{H}(2)$-uptake [NiFe] hydrogenase from Rhizobium leguminosarum bv. viciae, a legume endosymbiotic bacterium. Biochem. Soc. Trans. 33, 94-96. doi: 10.1042/BST0330094

Phelan, P., Moloney, A. P., McGeough, E. J., Humphreys, J., Bertilsson, J., O'Riordan, E. G., et al. (2015). Forage legumes for grazing and conserving in ruminant production systems. Crit. Rev. Plant Sci. 34, 281-326. doi: 10.1080/07352689.2014.898455

Ruiz-Argüeso, T., Imperial, J., and Palacios, J. M. (2000). Uptake Hydrogenases in Root Nodule Bacteria. Prokaryotic Nitrogen Fixation: A Model System for Analysis of a Biological Process. Wymondham, UK: Horizon Scientific Press. 489-507.

Sambrook, J., and Russell, D. W. (2002). Molecular Cloning: A Laboratory Manual. New Yok, NY: Cold Spring Harbor.

Sanchez-Canizares, C., Jorrin, B., Duran, D., Nadendla, S., Albareda, M., Rubio-Sanz, L., et al. (2018). Genomic diversity in the endosymbiotic bacterium Rhizobium leguminosarum. Genes 9:60. doi: 10.3390/genes90 20060

Schäfer, A., Tauch, A., Jäger, W., Kalinowski, J., Thierbach, G., and Pühler, A. (1994). Small mobilizable multi-purpose cloning vectors derived from the Escherichia coli plasmids pK18 and pK19: selection of defined deletions in the chromosome of Corynebacterium glutamicum. Gene 145, 69-73. doi: 10.1016/0378-1119(94)90324-7

Simon, R., Priefer, U., and Pühler, A. (1983). Vector Plasmids for invivo and in-vitro Manipulations of Gram-Negative Bacteria. Molecular Genetics of the Bacteria-Plant Interactions. Berlin, Springer-Verlag. 98-106. doi: 10.1007/978-3-642-69338-0_11

Tabata, S., and Stougaard, J. (2014). The Lotus Japonicus Genome Preface to the Volume. Compend Pl Genome: Xi-Xi. doi: 10.1007/978-3-662-44270-8

Torres, A. R., Brito, B., Imperial, J., Palacios, J. M., Ciampitti, I. A., Ruiz-Argueso, T., et al. (2020). Hydrogen-uptake genes improve symbiotic efficiency in common beans (Phaseolus vulgaris L.). Antonie van Leeuwenhoek 113, 687-696. doi: 10.1007/s10482-019-01381-6

Zhang, J. J., Shang, Y. M., Peng, S. S., Chen, W. F., Wang, E. T., de Lajudie, P., et al. (2019). Rhizobium sophorae, Rhizobium laguerreae, and two novel Rhizobium genospecies associated with Vicia sativa L. in Northwest China. Plant Soil 442, 113-126. doi: 10.1007/s11104-019-04168-w

Zhang, X. N., Ward, B. B., and Sigman, D. M. (2020). Global nitrogen cycle: critical enzymes, organisms, and processes for nitrogen budgets and dynamics. Chem. Rev. 120, 5308-5351. doi: 10.1021/acs.chemrev.9b 00613

Conflict of Interest: The authors declare that the research was conducted in the absence of any commercial or financial relationships that could be construed as a potential conflict of interest.

Copyright (c) 2021 Sotelo, Ureta, Muñoz, Sanjuán, Monza and Palacios. This is an open-access article distributed under the terms of the Creative Commons Attribution License (CC BY). The use, distribution or reproduction in other forums is permitted, provided the original author(s) and the copyright owner(s) are credited and that the original publication in this journal is cited, in accordance with accepted academic practice. No use, distribution or reproduction is permitted which does not comply with these terms. 